\title{
Awareness and Acceptance of Contraception in Postpartum Women in Our Tertiary Hospital in Central India
}

\author{
${ }^{1}$ Bharti Sahu, ${ }^{2}$ Priyadarshani Tiwari, ${ }^{3}$ Vidhi Uikey, ${ }^{4}$ Poorva Badkur
}

\begin{abstract}
Introduction: Contraception is an important intervention to reduce unwanted pregnancy and promote healthy and better living among women. As the population continues to rise, there will be overcrowding, a limiting of resources, and the quality of life will decline. India, as the first country in the world, initiated the National Family Planning program in the year 1951 with the objective of "reducing the birth rate to the extent necessary to stabilize the population at a level consistent with requirement of national economy."
\end{abstract}

Objectives: (1) To study awareness, acceptance, and preferred method of contraception among postpartum women. (2) To identify the reasons for rejection of contraceptive methods. (3) To contribute to the development of knowledge in the area of family planning.

Materials and methods: The study is a community-based cross-sectional observational study. The study was conducted among postpartum women in reproductive age group who delivered in our hospital in the Department of Obstetrics and Gynecology of Netaji Subhash Chandra Bose Medical College \& Hospital, Jabalpur, Madhya Pradesh, India. A total of 480 married women were interviewed in the local language using a pretested questionnaire. Their level of awareness, acceptance, and reason for acceptance/refusal was assessed.

Results: A total of $65.2 \%$ of women were aware of at least one method of contraception; $73.9 \%$ women were using a contraceptive at the time of study; $34.8 \%$ women were unaware of any health care facility providing contraceptives in the vicinity. Maximum number of women preferred intrauterine contraceptive device (IUCD; $38.8 \%$ ) as their first choice. Knowledge and practice of emergency contraceptive was very low. Main reason for nonacceptance of contraceptive was lack of knowledge and fear of side effects. Health professionals were the main source of knowledge.

Conclusion: There is till date lack of awareness of contraception in some postpartum women. Regular counseling is a must to all pregnant women from every health care center in a village to superspeciality centers in cities. Information should be provided about various methods of contraception and patient should be able to choose a method of her choice.

\footnotetext{
${ }^{1,2}$ Assistant Professor, ${ }^{3}$ Resident, ${ }^{4}$ Senior Resident

${ }^{1-4}$ Department of Obstetrics and Gynecology, Netaji Subhash Chandra Bose Medical College \& Hospital, Jabalpur, Madhya Pradesh, India
}

Corresponding Author: Poorva Badkur, Senior Resident Department of Obstetrics and Gynecology, Netaji Subhash Chandra Bose Medical College \& Hospital, Jabalpur, Madhya Pradesh, India, Phone: +919981757403, e-mail: poorvadoc@ gmail.com
Keywords: Contraception, Intrauterine contraceptive device, Pregnancy.

How to cite this article: Sahu B, Tiwari P, Uikey V, Badkur P. Awareness and Acceptance of Contraception in Postpartum Women in Our Tertiary Hospital in Central India. J South Asian Feder Obst Gynae 2017;9(4):327-330.

Source of support: Nil

Conflict of interest: None

Date of received: 9 October 2017

Date of acceptance: 5 December 2017

Date of publication: January 2018

\section{INTRODUCTION}

Contraception is an important intervention to reduce unwanted pregnancy and promote healthy living among women. The benefits of family planning have become increasingly recognized worldwide, including improved health, economic, and social outcomes for women and families, as well as public health, economic, and environmental benefits at the population level. ${ }^{1}$ It is the need of the hour.

India was the first country in the world to launch family planning program in 1952 (National population policy, 2000). ${ }^{2}$ As on March 1, 2011, India's population stood at 1.21 billion comprising of 623.72 million (51.54\%) males and 586.47 million (48.46\%) females. India, which accounts for world's $17.5 \%$ population, is the second most populous country in the world next only to China $(19.4 \%)$. ${ }^{3}$ By slowing the growth of a population, women have more earning potential and families are able to devote more resources to each child, resulting in reductions of poverty. Despite the known benefits of family planning, globally more than 120 million women aged 15 to 49 who are married or in a union have an unmet need for family planning.

This study is to assess the level of adoption of contraception among women who had delivered within 1 year and to identify the different variables that affect postpartum contraception.

\section{MATERIALS AND METHODS}

This is a cross-sectional questionnaire-based study carried out in the Department of Obstetrics and Gynecology of NSCB Medical College, Jabalpur, Madhya Pradesh, India. 
A total of 480 postpartum women were enrolled in the study. All postpartum women were briefed about the study and their consent was taken to be enrolled in the study. They were interviewed based on a predesigned questionnaire. The questionnaire elicited information regarding their age, educational status, income, awareness, and practice of the various male and female, temporary and permanent methods of contraception. They were counseled and allowed to choose a method of contraception of their choice.

\section{RESULTS}

Among the 480 women in the study group, more than $80 \%$ were in the age group of 15 to 30 years: $51.1 \%$ women from urban areas and $48.9 \%$ from rural areas of Jabalpur. Majority of the women were Hindus (89.8\%) followed by Muslims (6.9\%). Christians and Janis formed a minority; $80 \%$ of females were literate. Almost all were married and majority $(80.1 \%)$ of them were housewives (Table 1 ). Most of the women $(60.8 \%)$ had only one living issue and majority (48.5\%) had income between 3,000 INR and 5,000 INR per month.

Table 1 shows that awareness, earlier use, and acceptance were higher in the age group 26 to 30 years. It was observed that as age advances, awareness and acceptance increase. Awareness and acceptance were highest in educated, working, and women of higher socioeconomic groups. In our study, urban population was more aware

Table 1: Awareness, earlier use, and acceptance per sociodemographic profile

\begin{tabular}{|c|c|c|c|c|}
\hline Sociodemographic profile & No. of cases $(n=480)$ & Awareness $(n=313)$ & Earlier use $(n=98)$ & Acceptance $(n=355)$ \\
\hline \multicolumn{5}{|l|}{ Age group (years) } \\
\hline $15-20$ & $98(20.4 \%)$ & $53(54.1 \%)$ & $5(5.1 \%)$ & $62(63.2 \%)$ \\
\hline $21-25$ & $264(55 \%)$ & $177(67.1 \%)$ & $56(21.2 \%)$ & $204(77.3 \%)$ \\
\hline $26-30$ & $90(18.8 \%)$ & $72(80 \%)$ & $29(32.2 \%)$ & $72(80 \%)$ \\
\hline 31-35 & $25(5.2 \%)$ & $11(44 \%)$ & $8(32 \%)$ & $17(68 \%)$ \\
\hline 36-40 & $03(0.6 \%)$ & $00(0 \%)$ & $00(0 \%)$ & $00(0 \%)$ \\
\hline$p$-value & & $25.0(4) p=0.000$ & $24.80(4) p=0.000$ & $18.01(4) p=0.001$ \\
\hline \multicolumn{5}{|l|}{ Area } \\
\hline Rural & 235 (48.9\%) & $136(57.8 \%)$ & $42(17.8 \%)$ & $165(70.2 \%)$ \\
\hline Urban & $245(51.04 \%)$ & $177(72.2 \%)$ & $56(22.8 \%)$ & $190(77.5 \%)$ \\
\hline $\mathrm{p}$-value & & $10.09(1) p=0.001$ & $1.83(1) p=0.176$ & 3.35 (1) $p=0.067$ \\
\hline \multicolumn{5}{|l|}{ Religion } \\
\hline Hindu & $431(89.8 \%)$ & $279(64.7 \%)$ & $91(21.1 \%)$ & $316(73.3 \%)$ \\
\hline Muslim & $33(6.8 \%)$ & $20(60.6 \%)$ & $5(15.2 \%)$ & $24(72.7 \%)$ \\
\hline Others & $16(3.3 \%)$ & $14(87.5 \%)$ & $2(14.2 \%)$ & $15(93.7 \%)$ \\
\hline p-value & & $3.85(2) p=0.145$ & $1.31(2) p=0.520$ & $3.37(2) p=0.185$ \\
\hline \multicolumn{5}{|c|}{ Family income (INR per month) } \\
\hline$<3000$ & $161(33.5 \%)$ & $86(53.4 \%)$ & $23(14.2 \%)$ & $101(62.7 \%)$ \\
\hline $3,000-5,000$ & $233(48.5 \%)$ & $155(66.5 \%)$ & $56(24.1 \%)$ & $179(76.8 \%)$ \\
\hline $6,000-10,000$ & $79(16.5 \%)$ & $65(82.3 \%)$ & $16(20.2 \%)$ & $68(86.1 \%)$ \\
\hline$>10,000$ & $07(1.5 \%)$ & $07(100 \%)$ & $3(42.8 \%)$ & $7(100 \%)$ \\
\hline$p$-value & & $3.85(2) p=0.145$ & $1.31(2) p=0.520$ & $3.37(2) p=0.185$ \\
\hline \multicolumn{5}{|l|}{ Education status } \\
\hline Illiterate & $54(11.3 \%)$ & $10(18.5 \%)$ & $4(7.4 \%)$ & $16(29.6 \%)$ \\
\hline Primary & $231(48.1 \%)$ & $134(58 \%)$ & $46(34.3 \%)$ & $164(70.9 \%)$ \\
\hline Secondary & $103(21.5 \%)$ & $87(80.6 \%)$ & $20(19.4 \%)$ & $85(82.5 \%)$ \\
\hline Higher secondary & $50(10.4 \%)$ & $44(88 \%)$ & $14(20 \%)$ & $48(96 \%)$ \\
\hline Graduate & $33(6.9 \%)$ & $33(100 \%)$ & $9(27.2 \%)$ & $33(100 \%)$ \\
\hline Postgraduate & $09(1.9 \%)$ & $09(100 \%)$ & $5(55.6 \%)$ & $09(100 \%)$ \\
\hline$p$-value & & $108.96(5) p=0.000$ & $15.29(5) p=0.009$ & $87.47(5) p=0.000$ \\
\hline \multicolumn{5}{|l|}{ Occupation } \\
\hline Housewife & 456 (95\%) & $295(64.7 \%)$ & $91(19.9 \%)$ & $336(73.6 \%)$ \\
\hline Working & $24(5 \%)$ & $18(75 \%)$ & $7(29.1 \%)$ & $19(79.2 \%)$ \\
\hline$p$-value & & 1.07 (1) $p=0.301$ & $1.19(1) p=0.275$ & $0.36(1) p=0.551$ \\
\hline \multicolumn{5}{|l|}{ Parity } \\
\hline 1 & $292(60.8 \%)$ & $181(61.9 \%)$ & $24(8.2 \%)$ & $209(71.5 \%)$ \\
\hline 2 & $148(30.8 \%)$ & $103(69.6 \%)$ & $60(40.5 \%)$ & $112(75.6 \%)$ \\
\hline 3 & $35(7.3 \%)$ & $28(80 \%)$ & $13(37.1 \%)$ & $33(94.2 \%)$ \\
\hline$>3$ & $5(1.04 \%)$ & $1(20 \%)$ & $1(20 \%)$ & $1(20 \%)$ \\
\hline$p$-value & & $10.47(3) p=0.015$ & $69.65(3) p=0.000$ & $16.16(3) p=0.001$ \\
\hline
\end{tabular}




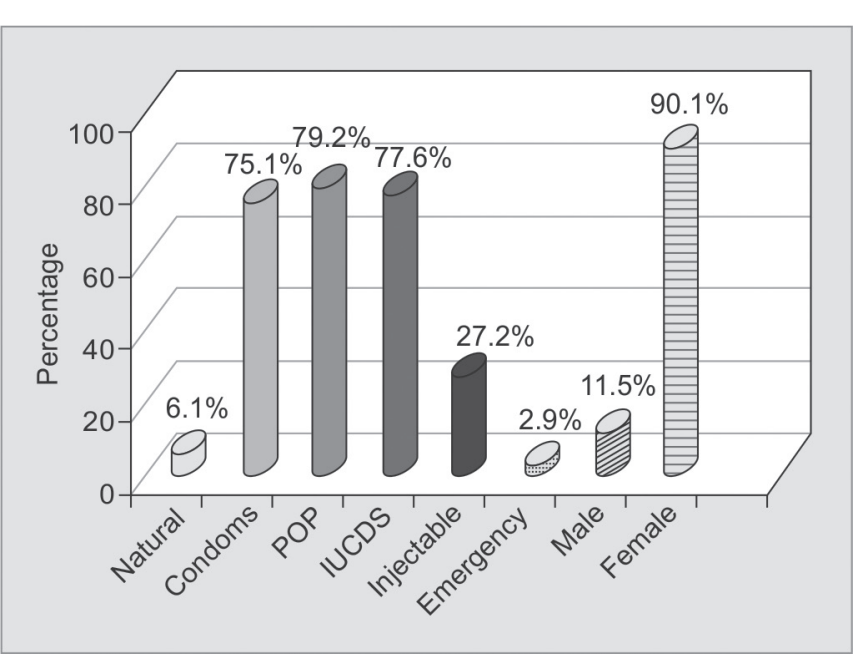

Graph 1: Awareness of the various contraceptive methods (\%)

Table 2: Distribution of cases according to contraceptive method practiced in present $(n=480)$

\begin{tabular}{lll}
\hline Contraceptive methods & Present & Percentage \\
\hline Natural & 11 & 2.3 \\
Condoms & 19 & 3.9 \\
OCPs/POP & 23 & 4.8 \\
IUCD & 233 & 48.5 \\
Injectable & 10 & 2.08 \\
Emergency contraceptives & 00 & 0 \\
Male sterilization & 00 & 0 \\
Female sterilization & 59 & 12.3 \\
None & 125 & 26.04 \\
\hline
\end{tabular}

and accepted contraceptives as compared with rural population. Acceptance was highest in women with two to three children. Maximum number of women were aware of female sterilization $(90.1 \%)$, progesterone-only pill (POP; 79.2\%), intrauterine device (77.6\%), and condoms (75.1\%; Graph 1). Knowledge regarding emergency contraception $(2.9 \%)$ was very low.

In our study, at present, $48.5 \%$ of postpartum women were using IUCD and $12.3 \%$ opted for female sterilization (Table 2). The main reason given by the women for nonacceptance was lack of knowledge and fear of side effects (Table 3). Main source of knowledge was health professionals (59.1\%) and mass media (Graph 2). When asked for her own choice, maximum women preferred $\operatorname{IUCD}(38.8 \%)$ as their first choice.

\section{DISCUSSION}

In our study, majority of women, i.e., $73.8 \%$ of cases, were in the age group of 21 to 30 years. This indicates that the younger women are more concerned about their health as well as the health of their family and thus more receptive toward postpartum contraception. The age-wise distribution also shows that the contraceptive awareness and usage increase as the age increases. Saini et $\mathrm{al}^{4}$ reported
Table 3: Reason for nonacceptance of contraception $(n=125)$

\begin{tabular}{lll}
\hline Reason & No. of cases & Percentage \\
\hline Lack of knowledge & 30 & 24 \\
Fear of side effects & 38 & 30.4 \\
Religious belief & 4 & 3.2 \\
Husband opposition & 6 & 4.8 \\
Not necessary & 26 & 20.8 \\
They want pregnancy & 11 & 8.8 \\
Preference of male child & 10 & 8 \\
\hline
\end{tabular}

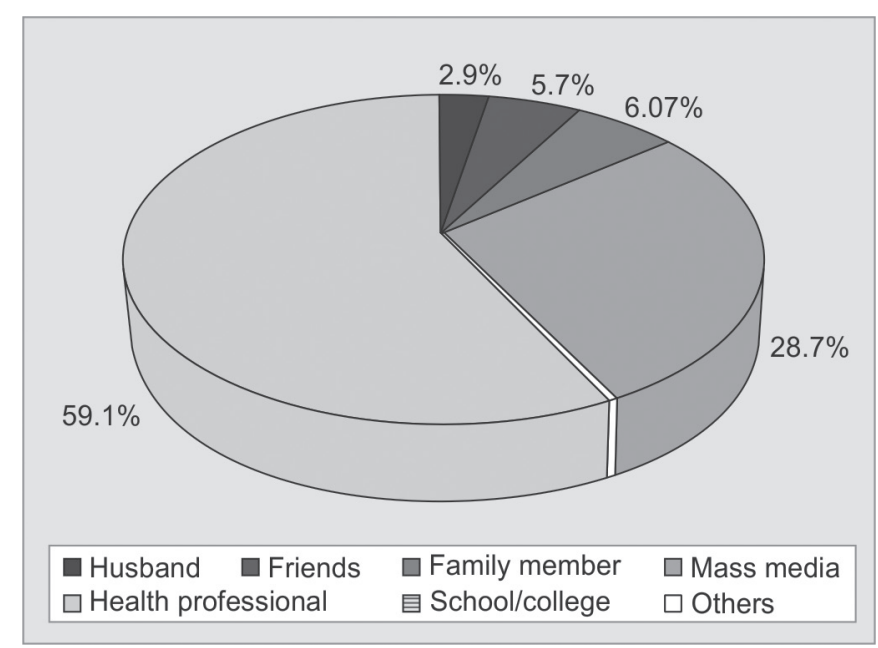

Graph 2: Source of knowledge about contraception

maximum users of spacing methods in the age group of 20 to 29 years $(63.7 \%)$.

In our study, awareness, earlier use, and acceptance were more in urban areas as compared with rural areas. According to Thyagarajan et al, ${ }^{5}$ respondents from urban areas are more likely to adopt a contraceptive method when compared with respondent from rural areas. Reason for this may be due to easy availability, higher literacy level, better socioeconomic condition, and easy access to health facilities in urban areas. Chaudhary ${ }^{6}$ reported that urban residence strongly influenced contraceptive use. Also in District Level Household and Facility Survey-3, $62.3 \%$ of urban population used contraceptives as compared with $37.7 \%$ in rural population. ${ }^{7}$

In our study, $65.2 \%$ of postpartum women were aware of at least one of the family planning methods, which is comparable to the study done by Thapa et $\mathrm{al}^{8}(69 \%)$, Ghike et $\mathrm{al}^{9}(67.5 \%)$, and Shrivastav et $\mathrm{al}^{10}(71.2 \%)$. The best known method of contraception was female sterilization $(90.1 \%)$, which is comparable to that of National Family Health Survey (NFHS)-3 (98\%) as well as a survey conducted in Uttar Pradesh (82.1\%).

The contraceptive prevalence rate among postpartum women in our study was $73.9 \%$. According to NFHS-3, the prevalence of modern contraceptive method in Madhya Pradesh is $56 \%$, which is similar to that of India as a whole $(56 \%) .{ }^{11}$ The contraceptive acceptance showed 
rising trends with increasing age, educational status, and family income. This is similar to the findings of a study conducted by Singh et $\mathrm{al}^{12}$ in Delhi.

The main reasons for nonacceptance were fear of side effect $(30.4 \%)$ and lack of knowledge (24\%). Singh et al ${ }^{12}$ reported fear of side effect $(24 \%)$ as the major reason in their study, followed by expectation of a male child $(8 \%)$, while Mahmood et $\mathrm{al}^{13}$ in their study reported lack of knowledge $(32.5 \%)$ as the main reason for not using contraceptives.

When $65.2 \%$ women who had knowledge of contraception were asked about their source of information on contraception, majority indicated that health professional was their source of information. Sharma et al ${ }^{14}$ reported $49 \%$ of women seeking advice from health professionals followed by $41 \%$ from mass media. An Ethiopian study showed that $80.3 \%$ of health personnel contributed in providing information regarding contraception (Graph 1).

After giving information about various family planning methods, women were asked for their own choice, and maximum number of women preferred IUCD $(38.8 \%)$ as their first choice followed by female sterilization (16.8\%). Oral contraceptive pills (OCPs), condoms, natural methods, and injectables were preferred by 7.9, $5,3.1$, and $2.3 \%$ of women respectively. In Thapa et $\mathrm{al}^{7}$ study, choices preferred by postpartum women were: $33.6 \%$ opted for IUCD, $20 \%$ for barrier method, $26.5 \%$ for Depo-Provera, $10 \%$ for progesterone pill, $3.9 \%$ preferred lactational amenorrhea method, and safe method 3\%.

\section{CONCLUSION}

It was observed from the present study that there is a lack of awareness of contraception in postpartum women. Regular counseling is a must to all pregnant women from every health care center in a village to superspeciality centers in cities. Information should be provided about various methods of contraception and patient should be able to choose a method of her choice. There is a lack of awareness of emergency contraception in postpartum women under study. There is need to strengthen the family planning services. It is essential to devise programs to spread awareness among women to use contraception to limit births, and it is also very essential to effectively devise and implement postpartum family planning programs in India by integrating them with maternal and child health services.

From the study, it can be inferred that postpartum period is a golden time when the advice is taken by the patient and implementation is higher, which restore her health for a long time. It was seen that women who receive counseling during hospital stay for delivery are more likely to use contraceptives in the postpartum period. So there is a need to observe more closely the role of family planning policies and health care providers in effectively generating motivation and knowledge among Indian women to use contraceptives in postpartum period.

The limitation of this study was that only a group of patients who seek health care in a tertiary center were interviewed. Hence, the finding in this study cannot be generalized to the state or to India as a whole. There is a need for proper promotion of spacing method by policymakers and field workers and motivation of couples to accept them so as to have healthy and wealthy India.

\section{REFERENCES}

1. Ram, U. Contraceptive Use among Young Married Women in India. International conference on family planning: research and best practices to be jointly organized by Bill and Melinda Gates Institute for Population and Reproductive Health, John Hopkins University, School of Public Health, USA, Makerere University, School of Public Health during November 15-18, 2009 at Munyonyo, Uganda.

2. National population policy 2000, cited 3rd march 1991.

3. Size, growth rate and distribution of population-census of India. 2011.

4. Saini NK, Singh M, Gaur DR, Kumar R. Awareness and practices regarding spacing methods in urban slums of Rohtak. Indian J Comm Med 2006 Apr-Jun;31(2):84-85.

5. Thyagarajan S, Reji B, Viswan SP. Determinants of contraceptive usage in India. IJIMS 2014 Oct;1(10):88-97.

6. Chaudhary RH. The influence of female education, labour force participation and age at marriage on fertility behaviour in Bangladesh. Soc Biol 1984 Spring-Summer;31(1-2):59-74.

7. International institute of population science (IIPS). District Level Household and Facility Survey (DLHS-3), 2007-08: India. Mumbai: IIPS; 2010.

8. Thapa S, Rani A, Mishra CP. Knowledge, attitude and belief about contraception in post partum and post abortal women in a tertiary care centre. Int J Reprod Obstet Gynaecol 2014 Sep;3(3):533-539.

9. Ghike S, Joshi S, Bhalerao A, Kawthalkar A. Awareness and contraception practices among women an Indian rural experience. JSAFOG 2010 Jan-Apr;2(1):19-21.

10. Shrivastav A, Khan MS, Chauhan CR. Knowledge, attitude and practices about contraceptive among married reproductive females. Int J Sci Study 2014 Feb;1(5):2-4.

11. National Family Health Survey (NFHS-3), India (internet). [cited 2011 Mar 15].

12. Singh M, Mehla S, Ranjan R, Das B. Awareness and acceptance of contraception in post-partum women in a tertiary care hospital Delhi. Int J Reprod Obstet Gynaecol 2015 Jun;4(3): 690-695.

13. Mahmood SE, Srivastava A, Shrotriya VP, Shaifali I, Mishra P. Postpartum contraceptive use in rural Bareilly. Indian J Community Health 2011 Jul-Dec;23(2):56-57.

14. Sharma SK, Pratap KC, Ghimire DR. Ethnic differentials of the impact of the Family Planning program on contraceptive use in Nepal. Demogr Res 2011 Dec;25(27):837-868. 